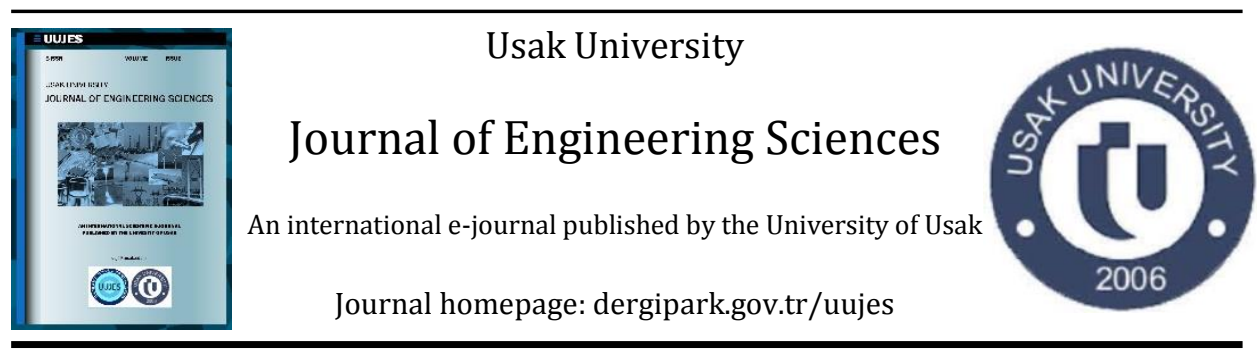

Research article

\title{
DESIGN OPTIMIZATION OF RECTANGULAR RC BEAMS USING GENETIC ALGORITHM
}

\author{
Jibrin Abubakar*, Benedict Anum, Cornellius T. Iaren \\ Department of Civil Engineering, University of Agriculture, Makurdi, Nigeria \\ Received: 13 May 2021 Revised:19 October 2021 Accepted: 9 November 2021 Online available:30 December 2021 \\ Handling Editor: Jülide Öner
}

\begin{abstract}
The study presents an optimal design of simply supported rectangular reinforced concrete beams based on the ultimate limit state philosophy of BS8110 and using genetic algorithm as optimization tool. An optimization model was formulated. The model consists of an objective function which focuses on minimizing the steel ratio of the beams and constraint equations which are focused on checking that all the requirements of BS8110 for the design of reinforced concrete beams are satisfied. Results obtained showed a difference of up to $46 \%$ and $12.6 \%$ in steel ratios obtained using the traditional approach and those obtained using the optimization model for singly and doubly reinforced concrete beams respectively, depending on the magnitude of the applied moment. The model has proved to minimize the final dimensions of rectangular reinforced concrete beams and by implication, the steel ratio even though all the requirements of the code were satisfied.
\end{abstract}

Keywords: Optimization, rectangular beams, reinforcement ratio, Genetic Algorithm.

(C)2021 Usak University all rights reserved.

\section{Introduction}

Reinforced concrete (RC) structures have significant compressive strength when compared to other construction materials. Besides possessing a reasonably high compressive strength, reinforced concrete structures are durable, multi-functional and cost much lower when it comes to maintenance as compared to other structures. RC structures are also, generally very good in resisting the effect of fire and damages due to water, and have been characterised to have long service life [1].

\footnotetext{
*Corresponding author: Jibrin Abubakar

E-mail: jibo008@yahoo.com (ORCID: 0000-0002-2278-4665)

DOI: $10.47137 /$ uujes.936917
}

(C)2021 Usak University all rights reserved. 
The conventional approach in the design of RC members does not completely optimize the use of materials. Most designs are based on the experience or technical know-how of the designer. The designer chooses grades of materials and cross-section dimensions by comparing it to his/her own personal past experience. This gives space to fixed rules of thumb for preliminary designs [2]. In the process of designing structural elements, the engineers makes assumptions at every step in view of structural and non-structural features such as atheistic, stiffness, element strength, serviceability and how easy or otherwise it can be constructed. In other words, the designer formulates optimal design criteria to achieve their best designs; therefore, this process of structural design may be considered as an optimum design. As a result, for a structural element (member) which is subject to the same support and loading condition, different reinforcement areas and member sizes are used by different Engineers. These reinforcement areas and member sizes have different implications in terms of cost and some may be highly un-economical when used even though they have met code (design) requirements [3]. This traditional approach, which is entirely dependent on assumptions with the effectiveness of the resulting design (which are never the same for different designers) directly linked to the experience of the designer is strenuous as it requires a lot of effort, costs more and encourages waste of construction materials. Therefore, the use of genetic algorithm in structural design optimization is a better alternative to "design based on engineer's past experience" [4].

Optimization is purely a mathematical aspect that deals with the finding of minimum or maximum of an established objective function that still satisfy the prevailing design constraints. Structural optimization on the other hand, entails using available optimization methods in deigning structures. The structural optimization problem is made up of an objective function which is formulated to minimize the cost, dimension, volume or area of a structure under some given constraints which are mostly based on limits set by the design code. These constraints may be in the form of serviceability limit states or mechanical properties of the structure. It is important to note that, even when the optimization is not directly related to the cost, it should be able to come up with a solution that satisfies all design requirements [5].

Optimization of reinforced concrete members is an intricate problem, due to the large number of variables and associated rigorous constraint that control the design process. The structural design process may be divided into four different stages: formulating the functional requirements, conceptual design, optimization and detailing [6]. An iterative procedure is often needed for each stage before the final solution is accomplished; a process that is normally carried out without considering the relative costs of steel, concrete, formwork, or other relevant costs or any other auxiliary information in case of genetic or evolutionary algorithms. In an optimal design the structural behaviour, design loads and geometrical constraints are specified and then the objective function is defined. The aim of this computerized procedure is to ascertain the geometry to attain the desired behaviour at the lowest possible section leading to lowest cost. Computer programmes have therefore, become very important tools in structural optimization.

In recent time, genetic algorithms (GA) have been widely used in solving various structural optimization problems [2]. GA is a technique that is classified under stochastic heuristic optimization techniques. As the name implies, it mimics Darwin's theory of evolution, where the individuals having the best traits in the population have greater chance of survival and are responsible for producing new off springs [7]. David [8] applied genetic programming in solving design problems in civil engineering. The author was able to obtain improved solutions by applying genetic algorithms in solving 
structural design problems. GA modifies the traits of individuals that are chosen from a present generation to produce new individuals that form a new generation. With GA, the population approaches optimality as the number of generations increases [3].

Structural elements designed to carry transverse loads are generally referred to as Reinforced Concrete Beams. As a result of this load, the beam is made to resist shear forces, bending moments and sometimes torsion across its span. Generally, concrete is known to be weak in tension and strong in compression. Compared to compressive strength, the tensile strength of concrete is only about $10 \%$ and as a result, the designs of reinforced concrete structures are done with the assumption that the concrete offers no resistance to tensile forces [9]. Hence, steel reinforcements are combined with concrete to resist the tensile forces. In a framed structure, beams transfer loads (from slabs, walls and other beams) to the columns they are resting on. Beams can be of different shapes and support conditions. They can be continuous, cantilevered or simply supported, depending on the number, type and position of the supports. The depth of the beam is dependent on the magnitude of the moment it is designed to resist, this consequently, determines whether a beam is to be designed as singly or doubly reinforced. [10].

This paper presents an optimal design of rectangular reinforced concrete beams using GA as an optimization tool. The study is motivated by the promising technique of genetic algorithm in optimization and the continuous search for optimum solutions to structural engineering design problems.

\subsection{Optimization of Structural Elements}

Several research works on structural optimization have been carried out in the past. Some of the pertinent literatures in the field of structural optimization; specifically, in the area of RC beams are summarized here. Using geometric programming as optimization tool, Chakrabarty [11] carried out a minimum cost design for singly reinforced rectangular concrete beams. Khaleel and Itani [12] automated the design of partially pre-stressed concrete girders. Sequential quadratic programming (SQP) was used as optimization tool. The author achieved an optimized volume of prestressing and non-prestressing steel reinforcement, and also, optimized dimensions and spacing between stirrups. Adamuet al [13] used the European Code to optimize the cost of singly reinforced concrete beams using the continuum type optimality criteria. The author successfully optimized, by an iterative process, a RC beam that is simply supported at one end and fixed at the other. Al-Salloum and Siddiqi [14] carried out design optimization of singly reinforced rectangular beams. The authors focused on minimizing the cost of the beam on the basis of the principles of the American Code (ACI 318-89). They were able to achieve an optimal solution with an objective function that includes the costs of steel reinforcement, concrete and formwork for a unit length of the beam. In a related study, Yousif and Najim [15], with the application of genetic algorithm optimized the cost design of reinforced concrete beams. The study however, used the ACI standard specification. Alex and Kottali [16] developed a program based on genetic algorithm to optimize the dimensions of a beam. The study however, considered the design of a cantilever beam only. 


\section{Formulation of the Optimization Model}

\subsection{Singly Reinforced Concrete Beam}

\subsubsection{Objective Function for Singly Reinforced Beam}

The objective function, which is the steel ratio, is derived using the stress block (through compatibility of strains) for singly reinforced concrete beam as shown in Fig. 1. The analysis using compatibility of strains relates the reinforcement strain, to the strain at crack, and also the internal forces acting in the concrete and reinforcement [17].

The design variables are the width of the beam $\left(x_{1}\right)$ and the effective depth $\left(x_{2}\right)$.

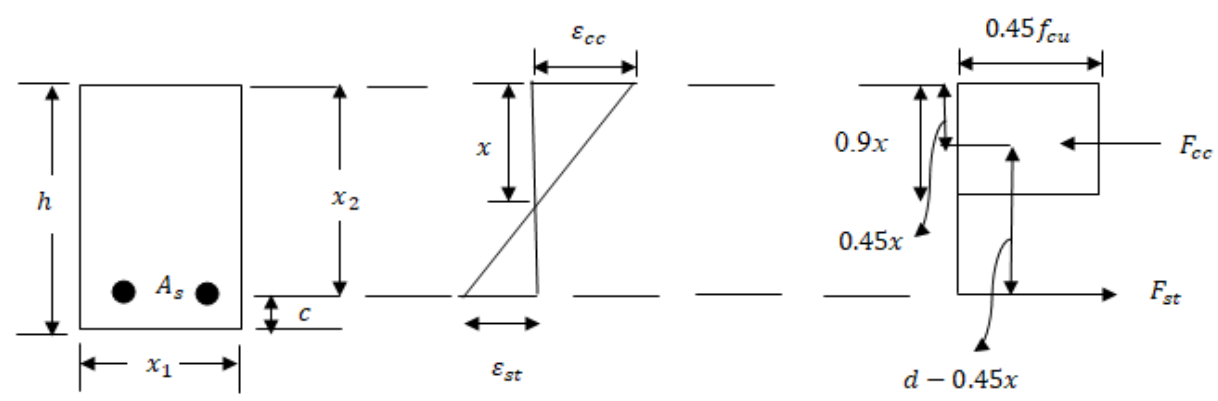

Fig. 1 Stress block for singly reinforced concrete beam

Let

$\mathrm{M}=$ ultimate moment of beam section

$f_{c u}=$ Concrete grade

$f_{y}=$ Steel grade

$x_{1}=$ Width of beam

$x_{2}=$ Effective depth of beam

$c=$ Concrete cover + half reinforcement diameter

$h=$ Overall depth of beam

$A_{s}=$ Area of tension reinforcement for singly reinforced beam

$f_{c c}=$ Force in the compression zone

$f_{s t}=$ Force in the tension zone

$\varepsilon_{c c}=$ Strain in the compression zone

$\varepsilon_{s t}=$ Strain in the tension zone

$\rho=$ Steel reinforcement ratio 


$$
\begin{gathered}
\frac{\varepsilon_{s t}}{x_{2}-x}=\frac{\varepsilon_{c c}}{x} \\
x \varepsilon_{s t}=\varepsilon_{c c}\left(x_{2}-x\right) \\
x\left(\varepsilon_{s t}+\varepsilon_{c c}\right)=x_{2} \varepsilon_{c c} \\
x=\frac{x_{2} \varepsilon_{c c}}{\left(\varepsilon_{s t}+\varepsilon_{c c}\right)}=\frac{x_{2}}{1+\frac{\varepsilon_{s t}}{\varepsilon_{c c}}}
\end{gathered}
$$

but

$$
\varepsilon_{c c}=0.0035 \text { and } \varepsilon_{s t}=\frac{0.95 f_{y}}{E_{s}}=0.00219
$$

Substituting these values in (1),

The neutral axis, $x=\frac{x_{2}}{1+\frac{0.00219}{0.0035}}=0.615 x_{2}$

The forces developed within the cross-section must be balanced by the applied force, P.

$$
\begin{gathered}
P=F_{c c}+F_{s t}=\sigma_{c c} A_{c c}-\sigma_{s} A_{s} \\
P=\sigma_{c c} A_{c c}-E_{s} A_{s} \varepsilon_{s t} \\
P=\left(0.45 f_{c u} \times 0.9 x x_{1}\right)-\left(E_{s} \times 0.00219 \times A_{s}\right)
\end{gathered}
$$

From (2), $x=0.615 x_{2}$

$$
P=0.25 f_{c u} x_{1} x_{2}-0.00219 E_{s} A_{s}
$$

Taking moment through the middle of the section,

$$
\begin{gathered}
M=F_{c c}(0.5 h-0.45 x)+F_{s t}\left(x_{2}-0.5 h\right) \\
\text { But } h=x_{2}+c \text { and } x=0.615 x_{2} \\
M=F_{c c}\left[0.5\left(x_{2}+c\right)-0.45\left(0.615 x_{2}\right)\right]+F_{s t}\left[x_{2}-0.5\left(x_{2}+c\right)\right] \\
M=F_{c c}\left(0.2232 x_{2}+0.5 c\right)+F_{c c}\left(0.5 x_{2}+0.5 c\right)
\end{gathered}
$$

But $F_{c c}=\sigma_{c c} A_{c c}=0.25 f_{c u} x_{1} x_{2}$ and $F_{s t}=\sigma_{s} A_{s}=0.00219 E_{s} A_{s}$

$$
M=0.25 f_{c u} x_{1} x_{2}\left(0.2232 x_{2}+0.5 c\right)+0.00219 E_{s} A_{s}\left(0.5 x_{2}+0.5 c\right)
$$

From (4),

Area of steel reinforcement, $A_{s}=\frac{M-0.25 f_{c u} x_{1} x_{2}\left(0.2232 x_{2}+0.5 c\right)}{0.00219 E_{s}\left(0.5 x_{2}+0.5 c\right)}$

$$
\text { Steel ratio, } \rho=\frac{\text { Area of steel }}{\text { Area of concrete }}=\frac{A_{s}}{x_{1}\left(x_{2}+c\right)}
$$

The objective function for singly reinforced beam is therefore,

$$
\rho\left(x_{1}, x_{2}\right)=\left[\frac{M-0.25 f_{c u} x_{1} x_{2}\left(0.2232 x_{2}+0.5 c\right)}{0.00219 E_{s}\left(0.5 x_{2}+0.5 c\right)}\right] \div\left[x_{1}\left(x_{2}+c\right)\right]
$$




\subsubsection{Design Constraints for Singly Reinforced Beams}

The design constraint equations are formulated based on the limits set by BS8110. The limitations of the optimization process are generally defined by the constraints. These constraints are conditions that govern the mechanical behaviour of the material, making sure that the conditions that guarantee the safety of the structural element are accounted for. BS 8110 has set limits for moment, minimum and maximum reinforcement ratios, cover-effective depth ratio and deflections for the safety and stability of the beam. These limits have been converted to constraint equations for the optimization problem.

\section{Moment constraint}

BS8110 provides that the ultimate moment, M should be less than $0.156 \mathrm{fu}_{\mathrm{ud}}{ }^{2}$ for the beam to be considered as singly reinforced.

$$
M \leq 0.156 f_{c u} x_{1} x_{2}^{2}
$$

\section{Minimum and maximum reinforcement constraint}

BS 8110 provides that the reinforcement ratios for beams must be between 0.13 and $6 \%$. This limit has been used to generate the following constraint equations

$$
\begin{gathered}
0.13-\left[\left(100 \times \frac{\left(M-0.25 f_{c u} x_{1} x_{2}\left(0.2232 x_{2}+0.5 c\right)\right)}{0.00219 E_{s}\left(0.5 x_{2}+0.5 c\right)}\right) \div\left(x_{1}\left(x_{2}+c\right)\right)\right] \\
\leq 0 \\
{\left[\left(100 \times \frac{\left(M-0.25 f_{c u} x_{1} x_{2}\left(0.2232 x_{2}+0.5 c\right)\right)}{0.00219 E_{s}\left(0.5 x_{2}+0.5 c\right)}\right) \div\left(x_{1}\left(x_{2}+c\right)\right)\right]-6 \leq 0}
\end{gathered}
$$

\subsection{Doubly Reinforced Concrete Beams}

\subsubsection{Objective Function for Doubly Reinforced Beam}

The objective function, which is the steel ratio, is derived using the stress block (through compatibility of strains) for doubly reinforced concrete beam as shown in Fig. 2. The design variables are the width of the beam $\left(x_{1}\right)$ and the effective depth ( $\left.x_{2}\right)$.

Let

$\mathrm{A}_{s t}=$ Area of tension reinforcement

$\mathrm{A}_{s c}=$ Area of compression reinforcement 


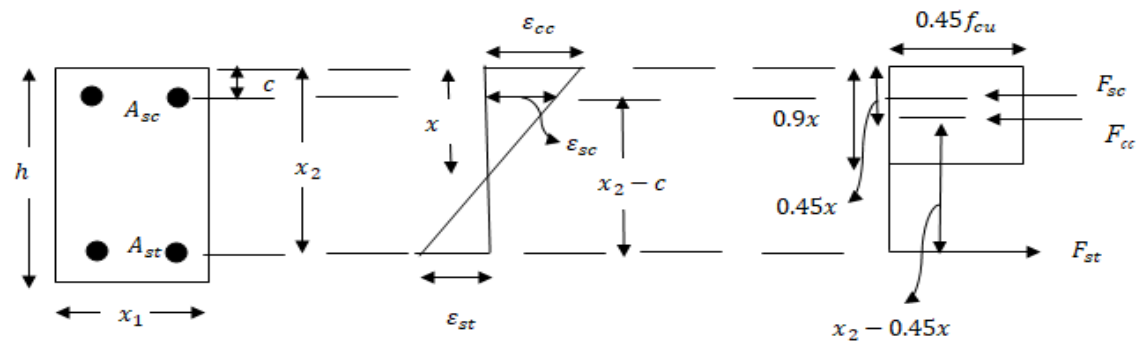

Fig. 2 Stress block for doubly reinforced concrete rectangular beam optimization From compatibility of strains

$$
\begin{gathered}
x=\frac{x_{2}}{1+\frac{0.00219}{0.0035}}=\frac{x_{2}}{1.6257}=0.615 x_{2} \\
F_{c c}=\sigma_{c c} A_{c c}=0.45 f_{c u} \times 0.9 x_{1} x=0.45 f_{c u} x_{1} \times 0.9 \times 0.615 x_{2} \\
F_{c c}=0.25 f_{c u} x_{1} x_{2} \\
F_{s t}=\sigma_{s} A_{s t}=E_{s} \varepsilon_{s} A_{s t}=0.00219 E_{s} A_{s t} \\
F_{s c}=0.00219 E_{s} A_{s c}
\end{gathered}
$$

Taking moment about the $F_{s t}$ axis

$$
\begin{gathered}
M=F_{c c}\left(x_{2}-0.45 x\right)+F_{s c}\left(x_{2}-c\right) \\
M=0.25 f_{c u} x_{1} x_{2}\left(x_{2}-0.45 \times 0.615 x_{2}\right)+A_{s c} \times 0.00219 E_{s}\left(x_{2}-c\right)
\end{gathered}
$$

From (14),

$$
A_{s c}=\frac{M-0.1808 f_{c u} x_{1} x_{2}^{2}}{0.00219 E_{s}\left(x_{2}-c\right)}
$$

Taking Moment at the neutral axis, at $\quad \mathrm{x}=0.615 \mathrm{x}_{2}$

$$
\begin{aligned}
M=F_{s t}\left(x_{2}-0.9\right. & \left.\times 0.615 x_{2}\right)+F_{c c}\left(0.615 x_{2}-0.45 \times 0.615 x_{2}\right) \\
& +F_{s c}\left(0.615 x_{2}-c\right)
\end{aligned}
$$

By substituting the values of $F_{s t}, F_{c c}$ and $F_{s c}$ in (16),

$$
\begin{array}{r}
A_{s t}=\frac{M-0.0845 f_{c u} x_{1} x_{2}^{2}-A_{s c}\left(0.615 x_{2}-c\right) \times 0.00219 E_{s}}{0.00219 E_{s} \times 0.446 x_{2}} \\
A_{s t}=\frac{M-0.0845 f_{c u} x_{1} x_{2}^{2}}{0.000978 x_{2} E_{s}}-A_{s c} \times \frac{\left(0.615 x_{2}-c\right)}{\left(0.446 x_{2}\right)} \\
A_{s t}=\frac{M-0.0845 f_{c u} x_{1} x_{2}^{2}}{0.000978 x_{2} E_{s}}-\left(\frac{M-0.1808 f_{c u} x_{1} x_{2}^{2}}{0.00219 E_{s}\left(x_{2}-c\right)}\right) \frac{\left(0.615 x_{2}-c\right)}{\left(0.446 x_{2}\right)}
\end{array}
$$

Total reinforcement area, $A_{s}=A_{s t}+A_{s c}$ 


$$
\begin{gathered}
A_{s}=\frac{M-0.0845 f_{c u} x_{1} x_{2}^{2}}{0.000978 x_{2} E_{s}}-\left(\frac{M-0.1808 f_{c u} x_{1} x_{2}^{2}}{0.00219 E_{s}\left(x_{2}-c\right)}\right) \frac{\left(0.615 x_{2}-c\right)}{\left(0.446 x_{2}\right)} \\
+\frac{M-0.1808 f_{c u} x_{1} x_{2}^{2}}{0.00219 E_{s}\left(x_{2}-c\right)}
\end{gathered}
$$

$$
\text { Steel ratio, } \rho=\frac{\text { Area of Steel }}{\text { Area of Concrete }}=\frac{A_{s}}{x_{1}\left(x_{2}+c\right)}
$$

The objective function for doubly reinforced beam is therefore,

$$
\begin{gathered}
\rho\left(x_{1}, x_{2}\right)=\left[\frac{M-0.0845 f_{c u} x_{1} x_{2}^{2}}{0.000978 x_{2} E_{s}}-\left(\frac{M-0.1808 f_{c u} x_{1} x_{2}^{2}}{0.00219 E_{s}\left(x_{2}-c\right)}\right) \frac{\left(0.615 x_{2}-c\right)}{\left(0.446 x_{2}\right)}\right. \\
\left.+\frac{M-0.1808 f_{c u} x_{1} x_{2}^{2}}{0.00219 E_{s}\left(x_{2}-c\right)}\right] \div x_{1}\left(x_{2}+c\right)
\end{gathered}
$$

\subsubsection{Design Constraints for Doubly Reinforced Beams} Cover-effective depth ratio

$$
\frac{c}{x_{2}} \leq 0.2
$$

\section{Ultimate moment}

$$
0.156 f_{c u} x_{1} x_{2}^{2}-M \leq 0
$$

Minimum and maximum compression reinforcement ratio

$$
\begin{aligned}
& 0.2-\left[\left(100 \times \frac{M-0.1808 f_{c u} x_{1} x_{2}^{2}}{0.00219 E_{s}\left(x_{2}-c\right)}\right) \div\left(x_{1}\left(x_{2}+c\right)\right)\right] \leq 0 \\
& {\left[\left(100 \times \frac{M-0.1808 f_{c u} x_{1} x_{2}^{2}}{0.00219 E_{s}\left(x_{2}-d^{\prime}\right)}\right) \div\left(x_{1}\left(x_{2}+c\right)\right)\right]-6 \leq 0}
\end{aligned}
$$

\section{Minimum and maximum total reinforcement ratio}

$$
\begin{gathered}
0.13-\left[\left(100 \times \frac{M-0.0845 f_{c u} x_{1} x_{2}^{2}}{0.000978 x_{2} E_{s}}\right.\right. \\
\left.-\left(\frac{M-0.1808 f_{c u} x_{1} x_{2}^{2}}{0.00219 E_{s}\left(x_{2}-c\right)}\right) \frac{\left(0.615 x_{2}-c\right)}{\left(0.446 x_{2}\right)}\right) \\
\left.\div\left(x_{1}\left(x_{2}+c\right)\right)\right] \leq 0 \\
{\left[\left(100 \times \frac{\left(M-0.0845 f_{c u} x_{1} x_{2}^{2}\right)}{0.000978 x_{2} E_{s}}-\left(\frac{M-0.1808 f_{c u} x_{1} x_{2}^{2}}{0.00219 E_{s}\left(x_{2}-c\right)}\right) \frac{\left(0.615 x_{2}-c\right)}{\left(0.446 x_{2}\right)}\right)\right.} \\
\left.\div\left(x_{1}\left(x_{2}+c\right)\right)\right]-6 \leq 0
\end{gathered}
$$




\section{Deflection}

Applied deflection,

$$
\begin{array}{r}
\alpha=\frac{5 w L^{4}}{384 E_{c} I_{c r}} \\
\frac{5 w l^{4}}{384 E_{c} I_{c r}}-\frac{L}{250} \leq 0
\end{array}
$$

where

$I_{c r}=$ Moment of inertia of cracked section is found using parallel axis theorem from the transformed section shown Fig. 3

$w=$ Unfactored live load

$E_{c=}$ Elastic strength of concrete

$I_{c r}=$ Moment of inertia of cracked section

$L=$ Length of beam

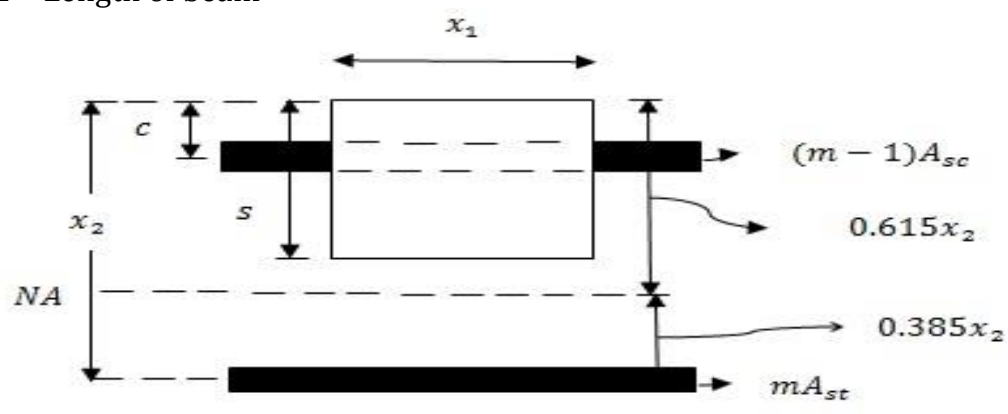

Fig. 3 Transformed concrete section

$$
\begin{gathered}
I_{c r}=\sum\left(I_{i}+A_{i} d^{2}\right) \\
I_{c r}=\left(0.385 x_{2}\right)^{2} m\left[\frac{M-0.0845 f_{c u} x_{1} x_{2}^{2}}{0.000978 x_{2} E_{s}}-\left(\frac{M-0.1808 f_{c u} x_{1} x_{2}^{2}}{0.00219 E_{s}\left(x_{2}-c\right)}\right) \frac{\left(0.615 x_{2}-c\right)}{(0.446 c)}\right] \\
+(m-1)\left(0.615 x_{2}-c\right)^{2}\left(\frac{M-0.1808 f_{c u} x_{1} x_{2}^{2}}{0.00219 E_{s}\left(x_{1}-c\right)}\right)+0.0774 x_{1} x_{2}^{3}
\end{gathered}
$$

\section{Results and Discussion}

After the designs were done for both manual (BS8110) and optimum (Genetic algorithm), it was observed that the following were optimized:

$>\operatorname{Beam}$ width $\left(x_{1}\right)$

$>$ Effective Depth $\left(x_{2}\right)$

$>$ Reinforcement Ratio $(\rho)$.

For this optimization, the following parameters were fixed

$\mathrm{f}_{\mathrm{cu}}=30 \mathrm{~N} / \mathrm{mm}^{2}$

$\mathrm{f}_{\mathrm{y}}=460 \mathrm{~N} / \mathrm{mm}^{2}$ 


$$
\begin{aligned}
& E_{S}=200 \times 10^{3} \mathrm{~N} / \mathrm{mm}^{2} \\
& E_{C}=26 \times 10^{3} \mathrm{~N} / \mathrm{mm}^{2} \\
& c=50 \mathrm{~mm}
\end{aligned}
$$

\subsection{Singly Reinforced Concrete Beams}

Table 1 shows a comparison of results obtained using the optimization model (with genetic algorithm) and those obtained using the traditional approach. It will be observed that the cross-sectional dimensions as well as the steel ratio for the beams are reduced when the optimization model is used even though the beams are subjected to the same moment. Fig. 4 shows a pictorial representation of the steel ratios. The steel ratios are reduced when the optimization model is used but are not directly proportional to the magnitude of the applied moment. This also applies to the beam cross-sections (the width and depth).

Table 1 The comparison between manual and optimization results for singly reinforced beam

\begin{tabular}{lccccccc}
\hline $\begin{array}{l}\text { Applied } \\
\text { Moment(kNm) }\end{array}$ & \multicolumn{3}{c}{ Traditional Approach } & \multicolumn{3}{c}{ Optimization model } & \multicolumn{1}{c}{$\begin{array}{c}\text { Difference } \\
\text { in } \rho \text { (\%) }\end{array}$} \\
\cline { 2 - 7 } & $x_{1}$ & $x_{2}$ & $\rho$ & $x_{1}$ & $x_{2}$ & $\rho$ & \\
116 & 270 & 465 & 0.0051 & 250 & 450 & 0.0046 & 9.8 \\
119 & 260 & 510 & 0.0058 & 250 & 500 & 0.0037 & 36.2 \\
133 & 240 & 470 & 0.0072 & 230 & 450 & 0.0065 & 9.7 \\
134 & 265 & 470 & 0.0053 & 250 & 450 & 0.0036 & 32.1 \\
141 & 210 & 420 & 0.0075 & 200 & 400 & 0.0069 & 8 \\
144 & 205 & 415 & 0.01 & 200 & 400 & 0.0098 & 2 \\
151 & 265 & 460 & 0.0054 & 250 & 450 & 0.0032 & 40.7 \\
163 & 260 & 510 & 0.0056 & 250 & 500 & 0.0036 & 35.2 \\
166 & 240 & 465 & 0.005 & 230 & 450 & 0.0027 & 46 \\
169 & 250 & 410 & 0.0079 & 230 & 400 & 0.0073 & 7.6 \\
\hline
\end{tabular}




\section{Optimization of Singly Reinforced Concrete Beam \\ (Reinforcement Ratio)}

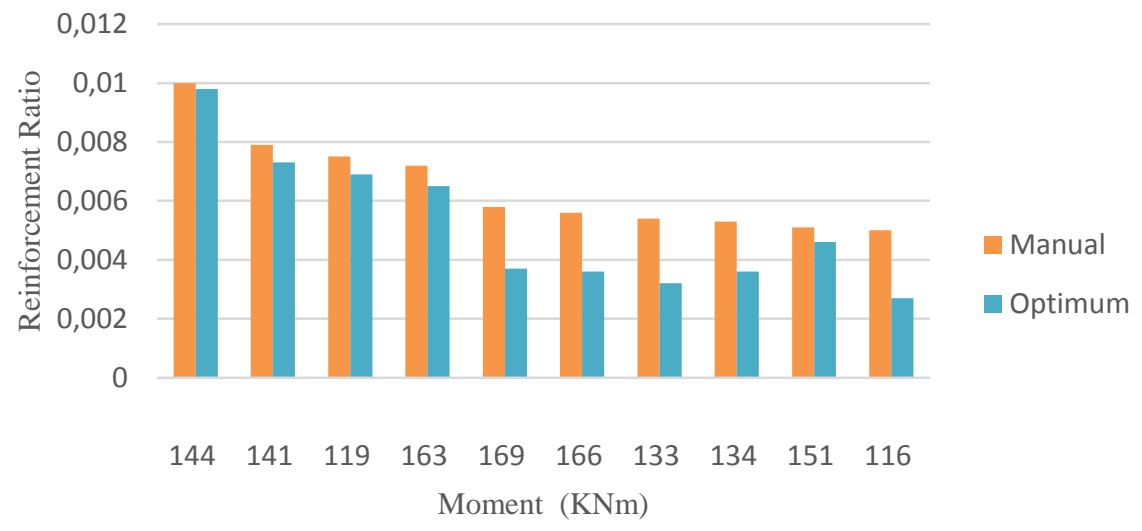

Fig. 4 The variation of the reinforcement ratios obtained using traditional and optimization approaches for considered moments (singly reinforced beam)

\subsection{Doubly Reinforced Concrete Beams}

A comparison was made between optimized and manual design and in each case, the optimized result was less than the manual result for reinforcement ratios as shown in Table 2 and Fig. 5

The length, elastic modulus of concrete (Ec), characteristic strength of concrete (fcu), width $\left(x_{1}\right)$ and effective depth $\left(x_{2}\right)$ of the beam were taken to be constant for both manual and optimized design and tried for random values of moment. The reinforcement ratios were found to be minimal with the optimization model with difference of up to $12.6 \%$ when compared with the manual (traditional) approach.

Table 2 The comparison between manual and optimization results for doubly reinforced beam

\begin{tabular}{ccccc}
\hline$x_{1}$ (mm) & $x_{2}$ (mm) & $\begin{array}{c}\rho \\
\text { (manual) }\end{array}$ & $\begin{array}{c}\rho \\
\text { (optimization) }\end{array}$ & Difference in $\rho \mathbf{( \% )}$ \\
\hline 250 & 300 & 0.063 & 0.0569 & 9.7 \\
230 & 300 & 0.0538 & 0.0488 & 9.3 \\
250 & 350 & 0.0484 & 0.0434 & 10.3 \\
250 & 400 & 0.0399 & 0.0356 & 10.7 \\
250 & 450 & 0.0319 & 0.0282 & 11.6 \\
250 & 450 & 0.0359 & 0.0319 & 11.14 \\
200 & 400 & 0.035 & 0.031 & 11.42 \\
230 & 450 & 0.0277 & 0.0243 & 12.27 \\
250 & 400 & 0.0305 & 0.0268 & 12.13 \\
250 & 450 & 0.0262 & 0.0229 & 12.6 \\
\hline
\end{tabular}




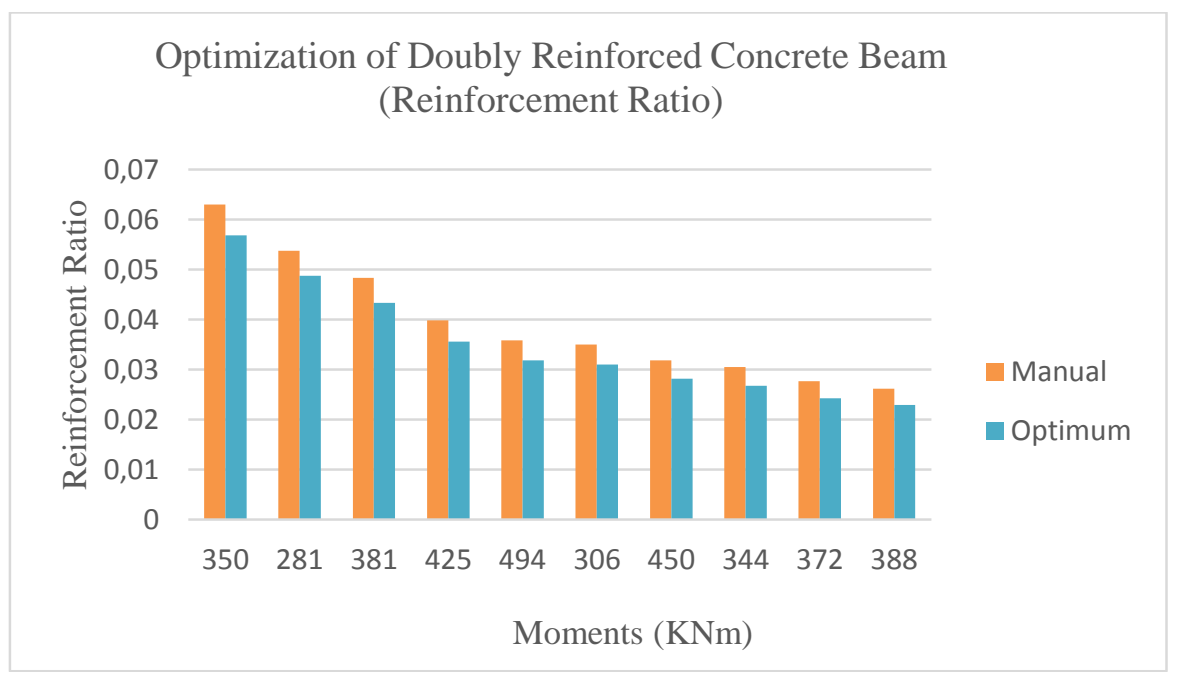

Fig. 5 The variation of the reinforcement ratios obtained using traditional and optimization approaches for considered moments (doubly reinforced beam)

\section{Conclusion}

The paper presents a design optimization model for simply supported reinforced concrete beams using Genetic Algorithm (GA) as an optimization tool. The model has proved to minimize the steel ratio for both singly and doubly reinforced concrete beams while satisfying design requirements of BS8110. Percentage difference in steel ratio as high as $46 \%$ and $12.6 \%$ for singly and doubly reinforced concrete beams respectively were obtained when the optimization model was compared with manual method in the design of reinforced concrete beams. By using the model, the cost of constructing simply supported beam is reduced significantly. However, the model can only be applied to simply supported rectangular reinforced concrete beams, other beam end conditions and shapes were not considered. The model is also almost ineffective in terms of minimizing the cross-sectional dimensions for doubly reinforced beams when compared to the traditional approach. It is only effective in minimizing the final reinforcement ratio. This indicates that only the area of reinforcement is minimized.

\section{References}

1. Wight JK and MacGregor JG. Reinforced concrete mechanics and design. New York: PEARSON; 2009.

2. Michalewicz, Z. Genetic algorithms + data structures = evolution programs. New York: Springer; 1992.

3. Abubakar J, Sadiku S, Tsado TY and Abdullahi M. Optimal design of slender reinforced concrete column subjected to axial load and uniaxial bending using the genetic algorithm approach: Faculty of Engineering International Conference (FEIC 2018); 2018 Aug 13-14; NnamdiAzikiwe University, Awka, Nigeria; 2018. p. 835-847.

4. Coello C A, Christiansen AD and Hernandez F. A simple genetic algorithm for the design of reinforced concrete beams, Engineering with Computers, 1997; 13: 185-196. 
5. Makoto 0. Optimization of finite dimensional structures. USA: CRC press; 2011.

6. Uri K. Structural Optimization: fundamentals and applications. New York: Springer-Verlag; 1993.

7. Don MA and Laju K. Genetic algorithm based design of a reinforced concrete cantilever beam, International Research Journal of Engineering and Technology (IRJET), 2015; 2(7): 1249-1252.

8. David EG. Genetic algorithms in search, optimization and machine learning. Boston: Addison Wesley; 1989.

9. Mosley WH, Bungey JH and Hulse R. Reinforced Concrete Design, New York: Palgrave; 1999.

10. MacGinley TJ and Chod BS.Reinforced concrete design theory and examples. London: Spon Press; 1990.

11. Chakrabarty BK. A model for optimal design of reinforced concrete Beams. Journal of Structural Engineering , ASCE, 1992; 118(11): 3238-3242.

12. Khaleel MA and Itani RY. Optimization of partially prestressed concrete girders under multiple strength and serviceability criteria. Computers and Structures, 1993; 49(3): 427-438.

13. Adamu A, Karihaloo BL and Rozvany GIN Minimum cost design of reinforced concrete beams using continuum-type optimality criteria. Structural optimization, 1994; 7: 91-102.

14. Al-Salloum YA and Siddiqi GH. Cost-optimum design of concrete Beams. ACI Structural Journal, 1994; 91(6): 647-655.

15. Yousif ST and Najem RM. Optimum cost design of reinforced concrete beams using genetic algorithms. The Iraqi Journal of Mechanical and Material Engineering, 2012; 12(4): 680-693.

16. Alex DM and Kottalil L. Genetic algorithm based design of a reinforced concrete cantilever beam. International Research Journal of Engineering and Technology, 2015 ; 2(7): 1249-1252.

17. Kaklauskas G. Crack model for RC members based on compatibility of stresstransfer and mean-strain approaches. Journal of Structural Engineering, 2017; 143(9): 1-13. 